\title{
Aspiraciones empresariales. Historia de vida de un pequeño empresario ${ }^{1}$
}

\author{
Antonio García-Nieto Gómez-Guillamón
}

Universidad de Murcia

\section{Resumen}

Este trabajo consiste en el análisis de la historia de vida de un pequeño empresario que nació en la década de 1920 y que, después de haber pasado por varias ocupaciones, fundó su propia empresa. El objetivo es relacionar las aspiraciones personales de los fundadores de empresas con el desarrollo y la evolución de la empresa. Las motivaciones personales del empresario se transfieren al modo de gestionar la empresa, condicionan su desarrollo y se manifiestan en las relaciones con los clientes, proveedores y empleados. En el análisis, se han seguido los procesos metodológicos derivados de la "teoría fundamentada», con un programa informático de análisis cualitativo.

Palabras clave: análisis cualitativo con ordenador, teoría fundamentada, cultura empresarial

\begin{abstract}
This investigation consists of an analysis of the life story of a small entrepreneur who was born in the twenties of the last century. The objective of the survey is to relate the personal aspirations of the company founder to the development and evolution of the company. The study attempts to show the conection between the entrepreneur's personal ambitions, and the way the company is managed, and how those aspirations affect the company's evolution, and his relationship with the clients, suppliers and employees. The methodology has been based on the Grounded Theory, usinng software for the Qualitative Data Analysis.
\end{abstract}

Key words: Qualitative Data Analysis, grounded theory, company culture.

\section{Sumario}

El empresario como producto social Fundación de la empresa y cultural Hipótesis Metodología Trayectoria empresarial

Conclusiones

Anexo de códigos

Referencias bibliográficas

1. Una primera versión de este documento se presentó en el Grupo de Trabajo de Bienestar Social de la Fundación CENTRA, en Granada. El autor agradece a Jaime Andreu, Pablo Galindo, Felipe Morente, Lorenzo Navarrete, José Ignacio Ruiz Olabuenaga y José Luis Villanueva, las sugerencias aportadas. 


\section{El empresario como producto social y cultural}

Las motivaciones empresariales responden a una lógica de aspiraciones que, aún teniendo rasgos comunes, es heterogénea (Nueno, 1994), se puede avanzar más desde el prisma sociológico apostillando que las motivaciones empresariales están determinadas por la propia situación personal del empresario y por los condicionantes sociales, culturales y económicos del entorno. El estudio de la motivación se ha desarrollado en el campo de la psicología, pero es preciso tener en cuenta que fue Talcott Parsons (1982) quien puso de manifiesto que la motivación es un elemento del sistema cultural que es utilizado por las personas en su acción dentro del sistema social. Ello significa que sistemas culturales y sociales distintos conducen al desarrollo de motivaciones diferentes. Las motivaciones empresariales son consideradas, en este trabajo, con ese significado de relación entre el sistema cultural y el sistema social.

La empresa es una organización y, como tal, siguiendo a Parsons (1982), tiene un sistema social que, a su vez, forma parte de un sistema social y cultural más amplio. En este aspecto, cada sociedad ha proporcionado unos rasgos culturales específicos a sus empresas, otorgándoles una singularidad característica (D’Iribarne, 1993; 1998). Como explicó Sainsaulieu (1997), la empresa no es un sistema social aislado y encerrado en sí mismo, al contrario, la empresa participa de todos los rasgos culturales (tradiciones, valores, instrucción, tecnología...) de la sociedad donde está insertada y, en este sentido, sus miembros son portadores de las particularidades culturales, sociales y económicas del entorno donde se desenvuelven. Por lo tanto, el empresario fundador pertenece a una cultura que ha influido en la formación de su personalidad y de su mundo interior y, de acuerdo con esas premisas, va implantando en la empresa sus creencias, sus valores y sus aspiraciones, lo cual configura la cultura de esa empresa (Schein, 1988).

Entre las diversas acepciones del término "empresario», Max Weber (1997) destacó su dimensión cultural e histórica, el espiritu del capitalismo se produce en sociedades que tienen determinadas condiciones que posibilitan las conductas emprendedoras, siendo el empresario la persona que desea obtener el lucro con un sentido ético de amor al trabajo y a la obra bien hecha. Schumpeter (1976) introdujo el significado de innovador, el empresario es la persona que dirige y realiza nuevas combinaciones, y la empresa es la organización donde se ejecutan. Por su parte, Collins, Moore y Unwalla (1964) utilizan una definición más sencilla que permite una mayor generalización. Para estos autores, el auténtico empresario es la persona que crea desde cero una empresa y la pone en funcionamiento. La acepción de empresario que se emplea en esta investigación es la de una persona con unos atributos sociales y culturales que crea y desarrolla un proyecto empresarial en consonancia con esos atributos.

\section{Hipótesis}

El eje central de esta investigación consiste en analizar cómo las motivaciones personales de un empresario se plasman en el acto de creación de una empresa y conducen el desarrollo empresarial posterior. Para Schumpeter (1976), las 
auténticas motivaciones empresariales suceden en los momentos iniciales de la empresa, cuando el emprendedor decide crear algo nuevo saliéndose de la rutina de la corriente circular económica, es entonces cuando el emprendedor adopta una conducta que es a la vez racional (pone en marcha nuevos planes) e irracional (no hedonista porque no busca la vida placentera). Concreta tres motivaciones básicas: la sensación de poder e independencia; el impulso de lucha y de obtener éxito, y el gozo creador de hacer cosas nuevas. Max Weber (1997) señala que el «tipo ideal» de empresario capitalista es el de una persona perseverante con un sentido ético de amor al trabajo y de cumplir buenamente con su profesión; no es un especulador, aunque tiene el deseo lógico de enriquecerse, aborrece el lujo y la ostentación. Max Weber también destaca la motivación no hedonista e irracional de los empresarios emprendedores capaces de romper con el tradicionalismo económico e iniciar nuevas vías. McClelland (1968) ha indicado que los empresarios son individuos que se caracterizan por tener una alta motivación de logro, que les impulsa a actuar con unos incentivos moderados confiando en sus posibilidades de éxito y desarrollando sus capacidades, pero sin ser aventureros o especuladores. Tanto en Schumpeter como en Weber y McClelland, ganar dinero no es fin en sí mismo, sino una medida del éxito.

Si los postulados anteriores se enmarcasen en la "gran teoría», la tipología de Lafuente, Salas y Pérez (1985) entraría en lo que Blumer (1982) denomina conceptos sensibilizadores que proporcionan una referencia y una orientación para dirigir la investigación. Estos autores, basándose en los resultados de una encuesta a pequeños y medianos empresarios, establecen una tipología de las aspiraciones y motivaciones de los empresarios relacionadas con sus características personales:

a) Artesanales. Sus aspiraciones están en la propia naturaleza del trabajo, que es su satisfacción personal.

b) De riesgo. Tienen una alta propensión empresarial, se adaptan a nuevas situaciones, afrontan incertidumbres, riesgos y retos, se preocupan de los aspectos organizacionales y conceden menos importancia al bienestar económico familiar.

c) Familiares. Su principal aspiración es el bienestar económico familiar, tienen una alta propensión para hacerse empresarios, se han formado como empleados en otras empresas o bien son autodidactas, les motiva a hacerse empresarios la independencia y la oportunidad de un negocio, su comportamiento empresarial es rígido y poco adaptativo, pero aceptan retos e incertidumbres. Son los empresarios de menor nivel de instrucción.

d) «Manageriales». Sus aspiraciones se centran en los resultados de su trabajo y en los aspectos organizativos.

Para acercarse al contexto económico y social en el cual el actor de esta investigación se hace empresario, hay que situarse en la década de 1950, en pleno franquismo. En contra de lo que pudiera parecer, el sistema político no favorecía la creación de pequeñas y medianas empresas, al contrario, imponía 
restricciones y limitaciones y desincentivaba el talento empresarial, centrándose en la gran empresa y, en especial, en la empresa pública (González, 1979; Jané, 1978; Tortella, 1994; Torres, 1995). A pesar de ese entorno poco propicio para la pequeña y mediana empresa, Jané (1978) indica que éstas fueron las que impulsaron el desarrollo económico español, por lo que se produjo una concentración empresarial en las unidades de pequeña dimensión, siendo los nuevos empresarios los verdaderos protagonistas del desarrollo, con una simbiosis entre pequeña empresa y empresario. Buena parte de los empresarios surgidos en los años cincuenta (se podría hacer extensivo a las dos décadas posteriores) procedían de capas sociales no acomodadas, tenían una formación deficitaria y efectuaron una movilidad social a través de la empresa (Linz y de Miguel 1963, 1964 a, b, c y d).

La hipótesis de aproximación es que el empresario dirige la empresa según sean sus aspiraciones personales, en este caso concreto, se trata de "aspiraciones familiares» (siguiendo la tipología de Lafuente, Salas y Pérez) centradas en el bienestar económico. En un contexto económico y social muy coercitivo, la creación de una empresa propiciaba una vía que permitía una posibilidad de mejora económica y ascenso en el estatus social.

\section{Metodología}

Esta investigación se sustenta en la historia de vida de un pequeño empresario, lo cual ha supuesto afrontar un reto metodológico, dada la reducida experiencia que hay en la sociología española en investigaciones donde se relaciona el discurso de los pequeños y medianos empresarios con la producción de los procesos sociales. Como indica Plumer (2001), las historias personales muestran la interpretación del sujeto de sus propias experiencias y del mundo que le rodea, por lo que revelan el interior de la persona con sus inquietudes morales, sus éxitos y sus fracasos. La historia de vida no tiene un enfoque intimista e individual, sino una perspectiva de totalidad, puesto que presenta la trayectoria vital de una persona en una estructura social y en un momento histórico concreto. Continuando con Plumer, la historia de vida relaciona a la persona con la historia de la sociedad de su tiempo, descubriendo las influencias recibidas por la estructura de valores y la estructura social y económica, y permite observar cómo esas influencias se reproducen de nuevo en la acción del sujeto dentro del sistema social. La elección de la persona informante es una cuestión metodológica básica en las historias de vida, es preciso que tenga una buena historia que contar, que sea representativo del entorno social que se estudia y, sobre todo, que conozca su propio universo cultural (Plummer, 2001). Con esas premisas, se ha seleccionado para este trabajo a un pequeño empresario que reúne unos rasgos muy significativos: nació a principios de los años veinte del siglo pasado, trabajó en varios empleos antes de fundar su empresa a principios de los años cincuenta y hasta el año 2004 permaneció con sus actividades empresariales, ha vivido diferentes etapas políticas sociales y económicas que se han sucedido en la historia de España. 
En el análisis del discurso de la historia de vida, se han utilizado herramientas metodológicas de la teoría fundamentada (grounded theory). Barney G. Glaser y Anselm L. Strauss (1999) presentaron, en 1967, la grounded theory como un proceso de generación de teoría basada en los datos de la investigación. Como, posteriormente, sus autores continuaron desarrollos diferentes, en esta investigación se ha seguido la línea de Anselm L. Strauss (fallecido en 1996), por entender que ofrece un enfoque más abierto y flexible (Strauss, 1996; Strauss y Corbin, 1998). Con esta premisa, han sido utilizados en esta investigación los elementos que proporciona la grounded theory, de manera abierta y adaptándolos al caso concreto (Andreu, García-Nieto y Pérez, 2007).

Para Strauss (1996), las herramientas analíticas tienen que ser simplemente instrumentos y no un fin en sí mismas, sin adoptar una posición cerrada acerca de una técnica específica o una determinada metodología, incluso incentiva la combinación de diferentes materiales en la investigación. En este aspecto, el análisis cualitativo de esta historia de vida se ha complementado con una comparación de los resultados de otros estudios, muchos de ellos de orientación cuantitativa, tratando de aproximarse a la integración de los métodos cualitativos y cuantitativos (Bericat, 1998).

La descripción de los datos es necesaria para mostrar lo que sucede, el escenario donde ocurren los hechos y cómo se comporta la gente. Ahora bien, el investigador no puede limitarse a hacer un relato, sino que debe involucrarse en la interpretación de los datos para aclarar por qué, cuándo, dónde y cómo ocurren los sucesos. La elaboración de teoría (theorizing) es un trabajo que supone concebir ideas y conceptos, y formularlos en un esquema lógico sistemático y explicativo (Strauss y Corbin, 1998). Muchos estudios cualitativos se quedan en la exposición del relato o simplemente en una descripción, la grounded theory pretende dar un paso más y tratar de explicar los fenómenos.

En la teoría fundamentada, el procedimiento de enfrentarse a los datos es denominado "codificación abierta» (open coding) (Glaser, 1978; Strauss, 1996; Strauss y Corbin, 1998), que consiste en «abrir» el texto y sacar a la luz los pensamientos, las ideas y los significados que se contienen en él, con el fin de descubrir, denominar y desarrollar los conceptos. En el proceso de microanálisis línea a línea (Strauss, 1996; Strauss y Corbin, 1998), los datos se descomponen, se conceptúan, y se etiquetan con un código que es un descriptor lógico de lo que está pasando. A la vez, se redactan los memorandos, que son anotaciones analíticas del investigador que reflejan sus pensamientos e interpretaciones sobre los datos y las categorías.

Para el análisis de los datos, ha sido empleado el programa informático de análisis cualitativo WinMax ${ }^{2}$, que permite seguir los procedimientos de la teoría fundamentada utilizando categorías, códigos y memorandos (Vallés, 2000, 2001; Cisneros, 2001; Andreu, García-Nieto y Pérez, 2007). Weiztman (2003)

2. Hay una nueva versión denominada Maxqda. 
recomienda utilizar los programas de análisis cualitativos como una herramienta de apoyo a las necesidades y a los objetivos del investigador, sin quedar atrapado en sus presunciones y posibilidades. Este programa, según indican sus autores (A. Kuckartz y U. Kuckartz, 2002), tiene su base teórica en la comprensión interpretativa de la acción social de Max Weber.

En el proceso de codificación, se han combinando los procedimientos inductivo y deductivo (Andreu, 2001). Los códigos empleados son del tipo descriptivos o códigos de notas. Los códigos han sido ordenados en familias de códigos, y en sistemas jerárquicos con subcódigos dependientes, de manera semejante a la codificación axial (axial coding) (Strauss, 1996; Strauss y Corbin, 1998), que establece distintos niveles de representación y explicación del fenómeno (en el anexo se presenta la codificación efectuada). Por último, el informe final se elabora con el soporte y la ayuda de los memorandos.

\section{Trayectoria empresarial}

\section{Orígenes familiares}

El protagonista de esta historia de vida, José ${ }^{3}$, nació en el año 1922 en Caravaca de la Cruz, una localidad situada en las tierras altas y serranas del noroeste de la región de Murcia, entre las provincias de Almería, Granada, Jaén y Albacete. En 1930, en Caravaca había 21.560 habitantes y era el quinto municipio en importancia demográfica de la provincia. En esos años, tenía una relevante y diversificada actividad económica: agricultura de secano y regadío, ganadería, explotaciones forestales, industria artesanal y agroalimentaria, y en servicios su área de influencia comercial alcanzaba a las localidades de las provincias limítrofes.

Los antecedentes empresariales ${ }^{4}$ de José se encuentran en el abuelo materno, que se dedicaba a la fabricación artesanal de alpargatas de esparto y las vendía en los mercados de los pueblos cercanos. El abuelo paterno era carabinero (policía de costas y aduanas), pero el padre se inclinó por la actividad comercial como viajante de una empresa de alpargatas de Caravaca.

Mi padre era viajante, tenía que estar viajando todo el año por la cantidad de familia que éramos, y cuando no viajaba ayudaba en la oficina, por que no le gustaba estar ocioso. Cuando venía, tenía bastante contacto con él y quería que le acompañara.

La situación económica de la familia era muy modesta. José, el mayor de ocho hermanos, mantenía unas relaciones muy estrechas con su padre: sentía admiración por él; se impregnó de su espíritu inquieto y apreciaba el vínculo

3. Nombre real.

4. Linz y de Miguel (1964d) señalaron que el 60\% de los empresarios tenía antecedentes empresariales en su familia. 
de cordialidad y amistad entre el padre y su jefe, exento de antagonismo y de enfrentamiento. El modelo del comportamiento paterno será imitado por el futuro empresario:

La familia del jefe de mi padre y nosotros teníamos una amistad muy íntima dentro de ser él el dueño y nosotros los empleados. Íbamos todos los años juntos a Águilas a tomar los baños, como se decía.

Sobre la influencia del padre y del ambiente familiar en los futuros emprendedores, Collins, Moore y Unwalla (1964) resaltan la existencia de unas relaciones paterno-filiales turbulentas que dejan una profunda huella psicológica en los futuros emprendedores y les conduce a una necesidad de exhibir sus deseos de autonomía y autorrealización. Aunque este aspecto ha sido muy remarcado por otros autores (Kets de Vries, 1977; Veciana, 1989), Collins, Moore y Unwalla se refieren también a situaciones de buena relación del tipo "padre pobre pero honesto», que corresponde a padres bien considerados en la comunidad, preocupados por el bienestar familiar que inician al hijo en sus habilidades profesionales. La situación familiar y, en concreto, la relación con el padre influye en la trayectoria vital del futuro emprendedor. Si esa relación es buena, sus enseñanzas le dejan un sedimento, tanto en los aspectos profesionales como en valores humanos y modos de comportamiento.

Varios son los autores que han destacado que los fundadores de empresas proceden de las capas sociales no acomodadas: Max Weber lo señaló en La ética protestante y el espiritu del capitalismo y, posteriormente, lo han recogido en investigaciones Collins, Moore y Unwalla (1964) y Bendix (1966), entre otros. En España, Juan Linz y Amando de Miguel (1963) y Picó (1976) han mostrado empíricamente la procedencia de estatus socioeconómico bajo de gran parte de los fundadores de empresas de los años cincuenta y sesenta 5 .

\section{Primer trabajo}

A los once años, José dejó la escuela, a pesar de la oposición del padre. Las clases le aburrían y se sentía más atraído por los asuntos comerciales. Tras una breve corta experiencia como botones en una entidad bancaria, entra, en junio de 1933, de aprendiz en un gran comercio de la localidad, con catorce dependientes y tres meritorios, donde se vendía todo tipo de mercaderías. Iniciar la vida laboral en puestos bajos era frecuente entre los fundadores de empresas

5. Linz y de Miguel (1963) indican que el $42 \%$ de los fundadores de empresas calificaban el estatus socioeconómico que tenían en su juventud de «ni bueno ni malo» o bien de «difícil». Este porcentaje aumenta al $49 \%$ para los fundadores de empresas de menos de 500 empleados.

Picó (1976), aplicando esa clasificación para los empresarios valencianos, señala que en esas categorías se posiciona el 61\% de los empresarios, que llegan al 67\% en las empresas regulares y pequeñas. 
en aquellos años ${ }^{6}$. Comenzar desde abajo permite a los futuros empresarios aprender el oficio desde los últimos escalones, conocer los entresijos, acumular experiencias y estimular el afán de superación.

Hasta que cumplió los catorce años, en 1936, no recibió José su primer sueldo. Los ingresos los obtenía de las propinas que recibía de los clientes, debido a esto, desarrolló cierta habilidad para conseguir que los clientes más remolones le dieran la propina. Además, José iba cultivando un espíritu mercantil con pequeñas actividades: les prestaba dinero a los dependientes a sueldo hasta que cobraran la paga, y como intereses le invitaban a la cerveza; aparte de esto realizaba trabajos artesanales, como pelotas de frontón y monederos de cuero, que vendía a sus amigos. Estas operaciones "financieras y mercantiles» las hacía con un sentido de amistad y camaradería con los «clientes», considerándose orgulloso de que lo apreciaran sus amigos y compañeros. Desde niño acuciado por la necesidad, tenía un gran interés por conseguir dinero con el sentimiento de realizar un servicio a los demás.

En el comercio, existía una jerarquía entre los empleados que se reproducía en el trato con los clientes: los empleados más antiguos y de mayor grado atendían a los clientes de posición social más alta, con una relación de reciprocidad jerárquica entre clientes y empleados. Sin embargo, José apreciaba un gran compañerismo, aunque a los empleados mayores (con más de veinte años de edad) los tratara en consideración a su puesto en el establecimiento.

Los aprendices con los empleados teníamos una familiaridad, tratándoles con el debido respeto, no es que les teníamos temor, sino que hablábamos con ellos y teníamos un trato muy agradable, si nos mandaban por la merienda o por cualquier cosa, pues nosotros con agrado se lo hacíamos y ellos lo reconocían.

La familia del empresario residía en una vivienda encima del comercio, se relacionaba con los empleados y los atendía cuando la ocasión lo requería. Al igual que le ocurría a su padre, José mantenía una relación cordial con su jefe, era amigo de los hijos y salía con ellos a divertirse junto con otros compañeros de trabajo.

Con los dueños nos llevábamos bien. Con uno de los hijos, que tenía un año más que yo, salíamos en muchas ocasiones juntos, jamás me trató a mí como a un empleado, con superioridad jamás, ni a mí ni a ninguno de los dependientes de ese comercio.

El clima laboral se desenvuelve en un ambiente de familiaridad y respeto mutuo, donde confluyen dos sistemas relacionales: el de los empleados entre sí

6. Juan Linz y Amando de Miguel (1964a) muestran que el 59\% de los fundadores había comenzado su vida laboral en trabajos manuales o administrativos de baja cualificación. Este porcentaje se elevaba al $83 \%$ en la «España en proceso de industrialización». 
y el del empresario con los empleados. Las relaciones entre los empleados no son competitivas, se acepta una estratificación donde cada uno tiene unas deferencias por la posición que ha adquirido en la jerarquía ocupacional. Las relaciones entre el empresario y los empleados son de compromiso mutuo y de lealtad exentas de conflictividad. El nuevo empleado es admitido en una comunidad que es una extensión de la familia del empresario. Éste lo acoge desde niño, le proporciona una educación, una iniciación al oficio, pero no le paga un salario hasta que pasan unos años. La empresa ofrece un camino para desenvolverse en la vida, y el empleado debe corresponder manifestando su aprobación a un sistema de valores y a una jerarquía establecida.

El sistema de relaciones basado en la lealtad, la sumisión y la adhesión de los empleados a los valores de la familia del empresario a cambio de una amplia protección, es denominado por Sainsaulieu (1997) «'esprit maison», y es propio de empresas familiares de pequeñas localidades. Este sistema de relaciones está insertado y articulado en el tejido social de la comunidad local y se reproduce en el seno de la empresa. Es un sistema de relaciones jerarquizado y estable, donde cada actor tiene su estatus y representa su papel dentro de unas normas comúnmente aceptadas.

Las tareas de un aprendiz de comercio proporcionan un proceso de aprendizaje para una persona observadora y dispuesta a adquirir conocimientos: desarrolla habilidades para obtener ingresos; adquiere destreza para relacionarse con los clientes y descodificar sus necesidades y gustos y aprender los entresijos sobre el comportamiento de las personas ante los demás ${ }^{7}$. Son las primeras lecciones de un futuro empresario en una escuela que no es académica, sino práctica.

Tuve mucha escuela cuando estaba en el comercio [...] Entraba toda clase de público $[\ldots]$ aquello te da cierta experiencia, porque estás tratando con mucha gente y luego los aprendices les llevábamos los encargos a su casa. Yo conocía prácticamente a todo el pueblo, hasta el extremo de saber quien era más tramposo o menos tramposo.

\section{Estudios}

Siendo empleado de comercio, José se percata de la importancia de la formación para la vida. No sigue una enseñanza oficial, cuando termina el trabajo, acude a casa de un maestro anarquista que ni siquiera tenía el título. Esta forma de enseñanza, bastante extendida en España durante muchos años, era utilizada por los jóvenes que no podían asistir a la escuela:

Yo ya tenía más inquietudes al tener más edad, yo vi que allí en la tienda, pues sí, era porvenir, pero yo tenía que tener una cultura un poco mayor. El señor

7. Sobre estos aspectos, véase: GOFFMAN, ERVING [1959] (2001). La presentación de la persona en la vida cotidiana. Buenos Aires: Amorrortu. 
que se dedicaba a dar clases, que estaba inválido, daba clases todo el día hasta la noche, y yo, cuando salía por la noche del comercio, entonces iba a clase. Nos cobraba una peseta todos los meses. Era un hombre que se significó bastante en la Guerra, era de la FAI. Aquel hombre era muy rígido, no había tenido estudios pero había leído mucho y era un hombre que estaba muy bien preparado. Al terminar la Guerra Civil, fue de los primeros que fusilaron.

Después de la Guerra Civil, José seguía pensando que, para poder progresar en la vida, tenía que formarse mejor. Realizó estudios de comercio del mismo modo, recibiendo clases de contabilidad en casa de un intendente mercantil que, por ser de izquierdas, fue depurado como empleado de una fábri$\mathrm{ca}^{8}$. Entre 1939 y 1941, José asistía a las clases por la mañana antes de ir al trabajo, y estudiaba después de salir del trabajo con otros dos compañeros. Aprobó los exámenes de contable mercantil en la Escuela de Comercio de Murcia, pero no recogió el título porque estimaba que el dinero de la tasa era más necesario en casa. Los otros dos compañeros tampoco recogieron el título, sin embargo, a los tres, los conocimientos de contabilidad les resultaron muy útiles para sus empleos ${ }^{9}$ :

Ya al terminar la Guerra, yo vi que aquello [el comercio] era bastante bueno y sano, pero no era lo que yo buscaba, yo pretendía más, yo quería llegar a más. Había un profesor que era intendente mercantil, nos daba clase a media docena porque lo dejaron cesante de la fábrica de chocolate por haberse significado de izquierdas. Con este señor, íbamos a dar clase de las seis y media de la mañana hasta las ocho y media, que es cuando entraba yo al comercio [...] Vinimos a Murcia a examinarnos a la Escuela de Comercio de contable mercantil y aprobamos. Al terminar nos dice estas palabras el director: «Habéis aprobado, ya no os falta más que el título». Yo le dije: «Mire usted, yo el título no me lo puedo sacar porque gano 93,75 y el título vale 75 pts. En mi casa hacen más falta las 93,75 que el título colgado».

José no tuvo una vida de estudiante propiamente dicha. Desde que abandonó la escuela a los once años, no cursó estudios en centros educativos, se consideraba un empleado que estudiaba. Sus maestros eran personas que se encontraban al margen del sistema establecido. José se desenvolvía en un sistema social muy reglado y estricto, pero no por ello dejaba de relacionarse con personas extrasistema, especialmente si le aportaban algo. Mostró, desde su adolescencia, un espíritu tolerante y abierto que iba a mantener a lo largo de su vida.

Hay una motivación personal por aprender, pero con un sentido utilitarista de mejorar en la escala social. El sujeto actúa con un fin distinto al méri-

8. Después de la Guerra Civil, los empresarios podían despedir a los empleados desafectos al régimen franquista (Cabrera y del Rey, 2002).

9. Linz y de Miguel (1963) indican que, entre los fundadores de origen modesto, son bastantes los que tienen estudios mercantiles. 
to académico, la consecución del logro no consiste en obtener un título, sino en adquirir una serie de conocimientos para poder progresar en la vida. El emprendedor valora la educación con un significado práctico y funcional: aplicar las enseñanzas adquiridas y obtener de ellas un beneficio (García-Nieto, 1999).

\section{Relaciones juveniles}

Aunque, en investigaciones ${ }^{10}$ y en autobiografías de empresarios ${ }^{11}$, se resaltan infancias y adolescencias duras y tristes, José considera que, a pesar de las dificultades económicas y de la vida atareada con el trabajo y los estudios, esos años fueron felices, se divertía, tenía una pandilla y lo pasaba bien con los amigos. "Yo tuve una buena peña de amigos y nosotros disfrutábamos mucho».

José vivía en un barrio industrial de pequeñas fábricas y talleres, pero, aunque allí tenía amigos, se integró en el ambiente urbano relacionándose con empleados de banca, oficinas o comercio del centro de la ciudad. Hay una línea divisoria entre los trabajadores del barrio y los del centro: el empleado urbano de cuello blanco se posiciona así mismo y, a la vez, es percibido socialmente en un estrato superior al del trabajador industrial de mono azul. Integrarse en el ambiente de los empleados de cuello blanco, significaba pertenecer a un grupo mejor considerado socialmente:

Vivía en el barrio donde estaba la fábrica de alpargatas, pero... Como yo ya leía y me preparaba, yo me codeaba con la gente del centro, que es donde estaba la gente más preparada, los escribientes de los bancos, los otros dependientes, con todos.

\section{Guerra Civil. Pensamiento político}

José vivió la guerra en una pequeña ciudad de retaguardia de la España republicana. José tuvo que hacer de cabeza de familia en esa época de penuria y escasez. Su padre estuvo en el frente con los «rojos» y no regresó hasta después de la guerra, tras haber estado preso en un campo de concentración de los «nacionales». A pesar del enfrentamiento civil, José piensa que, entre los vecinos, no había rencillas por motivos políticos. Las acciones violentas fueron protagonizadas por un grupo de fuera de la localidad que fusiló a personas de derechas en el castillo. A José, estos hechos le causaron una fuerte impresión y piensa que la gente del pueblo no habría actuado así. Tampoco aprueba la represión realizada por los nacionales en la postguerra, que fusilaron a personas de su entorno (un compañero de trabajo y su maestro anarquista), y cree que fue una venganza por los fusilamientos durante la guerra.

11. José Lladró (2002). 
La percepción que tiene José de las relaciones entre las clases sociales de la localidad es de armonía y de convivencia sin conflictividad ni enfrentamientos, aunque cada persona tenía sus ideas. José describe la estructura social como «una gran clase media más acomodada o menos acomodada, pero todos en el mismo grupo, con pocos ricos que no trataban mal a los pobres». José adopta una posición política de tolerancia con las distintas ideas y planteamientos de los demás, sin una participación activa ni en organizaciones empresariales ni políticas $^{12}$.

\section{Viajante}

En el año 1941, la familia se trasladó a Molina de Segura, donde su padre obtuvo un empleo de viajante en una empresa de conservas vegetales, sector que estaba propiciando un modelo económico más dinámico. José se colocó de oficinista en la misma empresa y, como complemento, se dedicó a la venta de libros. Esta segunda ocupación fue otro entrenamiento para la actividad empresarial. Organizó su propio sistema de cobros y pagos y agudizó su destreza comercial. Además de obtener un beneficio económico, se alegraba de que los libros fueran útiles a los clientes en sus profesiones. Tenía un gran espíritu de trabajo auspiciado por necesidades materiales y una motivación para aumentar el bienestar económico familiar.

En 1946, después del servicio militar, inició una nueva etapa con un empleo de viajante en una fábrica de conservas. La forma de vida del viajante en los años de la postguerra no era precisamente cómoda: viajaba en trenes poco confortables, comía lo que podía, se hospedaba en sencillas fondas y solucionaba por sí mismo los percances que se presentaban. Por las noches, José leía novelas de El Coyote ${ }^{13}$ para matar el aburrimiento y la soledad. Tenía ilusión e interés por trabajar, pero, cansado de esa forma de vida y con problemas de salud, José dejó el «viaje»y, a principios de 1953, obtuvo un empleo en Murcia de representante de una empresa de envases de cartón de Barcelona ${ }^{14}$. El oficio de viajante fue una etapa más en el aprendizaje empresarial: profundizó en los intríngulis del complejo mundo de las ventas; aprendió a resolver los problemas por sí solo, y conoció otras tierras y otras gentes.

La fórmula era veinticinco pesetas de dietas, un kilométrico de tercera y comisión, eso era todo lo que les daban a los viajantes. Yo pasé hambre, porque en el año 45 aún se pasaba hambre. Recuerdo que en algunos pueblos donde el tren llegaba con retraso, incluso dos horas después de la hora debida, habían cerrado el comedor, parece que estaban deseando cerrar el comedor porque esca-

12. Juan Linz y Amando de Miguel (1966) pusieron de manifiesto la indiferencia del empresario, especialmente del pequeño y mediano empresario, hacia las instituciones empresariales del franquismo y, en general, hacia el régimen franquista.

13. Novelas del oeste muy populares en aquella época.

14. Un paso previo de comercial en otra empresa fue una actividad bastante común de los nuevos empresarios (García-Nieto, 1999). 
seaba la comida. El recurso mío cuando ya era tarde, a las diez o a las once de la noche, pues si llevaba varios botes de muestras de mermelada y cogía un bote y me tomaba parte del bote, y del grifo me bebía un vaso de agua... Andábamos trabajando mucho, porque no podíamos perder tiempo con las vacaciones y eso... Saqué una experiencia que, de estar aquí metido en un pueblo, no hubiera tenido... Lo que quería era conocer todo, conocía el África que pertenecía al Gobierno español, pero luego pasé a Tánger, a la zona de Casablanca, Rabat, todo eso lo viajaba yo... Hasta ya se dio el caso a ver si yo me podía dejar el viaje porque empecé a padecer del estómago y demás, hasta que ya me lié la manta a la cabeza al final del 52 y dije "ya no viajo más» y cogí algunas representaciones... En fin, aquello fue una época, por eso me gustaba el viaje, aprender y conocer y todas esas cosas.

\section{Fundación de la empresa}

Con la representación del cartón, José captó una oportunidad de negocio. En Murcia se empleaban muy poco los embalajes de cartón, las empresas conserveras los utilizaban de madera, y entre Valencia y Murcia no había ninguna fábrica de cartón. En el año 1953, con su cuñado como socio "capitalista», instaló una sencilla fábrica de embalajes de cartón en Molina de Segura. A los dos años, como al cuñado no le interesaba el negocio, decidieron separarse de mutuo acuerdo y José se hizo cargo en solitario de la empresa. Fue un pionero en este negocio, se enfrentó con un producto poco conocido a la conquista de un mercado que creía que tenía posibilidades.

Antes de llegar a ser empresario, José había pasado por una dilatada trayectoria vital que había configurado su aprendizaje empresarial. Collins, Moore y Unwalla (1964) señalan que el camino del emprendedor es largo, solitario y difícil, y requiere un riguroso periodo de formación que no se enseña en las escuelas de negocios, sino en la universidad de la vida.

José, a la edad de treinta y un años, dejó de ser empleado pensando que, con tesón, podría progresar y llegar a tener un negocio que le permitiera vivir de manera desahogada ${ }^{15}$. Tenía como grupo de referencia a los empresarios de las industrias conserveras, bastantes de ellos habían empezado desde cero y estaban prosperando en sus negocios. La decisión de hacerse empresario le supuso a la persona dar un paso decisivo, el emprendedor aceptó un cambio en el modo de vida y de pensamiento. Este momento inicial es denominado, por Collins, Moore y Unwalla (1964), el «acto del emprendedor», mediante el cual la idea empresarial forjada durante algún tiempo se lleva a la práctica. Este acto supone una ruptura con el estilo de vida anterior, se produce un proceso crítico de «deterioro del rol» de empleado, hacia la realización del nuevo rol

15. Linz y De Miguel (1964d) realizan una curiosa comparación entre las oportunidades de la sociedad española y las de la sociedad norteamericana de los años veinte, y llegan a la conclusión de que son similares. Las diferencias residían en que el peso del sector industrial era menor en España y, además, «las instituciones políticas, la ideología nacional, hacía y hacen que el obrero americano creyera en sus oportunidades y el español no» (p. 46). 
de emprendedor para el cual se habían estado preparando en los empleos anteriores:

Me motivó a instalarme por mi cuenta que, con las representaciones, estaba viendo que todos los representantes que había en Molina vivían malamente o muy escasamente en aquella época. Después ha evolucionado, pero entonces, como se solía decir, no sacaban los pies del plato, y yo lo que ambicionaba era otra cosa que a mí me diera de comer más cómodamente, que con el tiempo yo pudiera tener cierta comodidad. Esto que digo fue en el 53, yo ya tenía treinta y un años y no veía el porvenir muy halagüeño, y lo que me decidió a lanzarme fue eso... Yo pretendía otra cosa, puesto que yo había visto que los que se habían establecido de exportadores, como fue Hernández Pérez, como fue Hernández Contreras y como fueron muchos, todos iban adelante, pues pensé que yo podría quizás tener con tesón la posibilidad de un negocio que me diera de comer desahogadamente y poder prosperar.

La motivación principal de José para realizar el «acto de emprendedor» fue la mejora económica, quería ganar más dinero para poder vivir con mayor comodidad. A lo largo de su vida, hay constantemente un deseo de superación y de salir de su situación socioeconómica. Esta motivación se ajusta plenamente al tipo «familiar» donde el mayor interés se centra en conseguir un mayor bienestar (Lafuente, Salas y Pérez, 1985). Establecer la empresa propia era, para las personas sin recursos económicos y sin estudios, una de las pocas oportunidades que tenían de ascender económica y socialmente ${ }^{16}$.

\section{Comienzos de la empresa}

Los comienzos de la actividad empresarial suponen enfrentarse a dificultades de todo tipo, especialmente económicas. Aunque se dedicó a una clientela local, la introducción comercial fue lenta, puesto que las empresas conserveras utilizaban envases de madera. Hasta que se consolidó la empresa, José realizó una actividad multifacética, trabajaba en todas las tareas de la fábrica: por falta de personal especializado, tenía que hacer de mecánico ${ }^{17}$, atendía la oficina, iba a comprar a las fábricas de cartón y salía a vender a los clientes. El sentido del esfuerzo, del sufrimiento y del trabajo son valores que se encuentran muy arraigados en este tipo de empresarios, sin estos valores, en ese entorno tan adverso, no hubieran podido desarrollar y mantener la empresa (García-Nieto, 1999):

16. Linz y De Miguel (1964c), al analizar la movilidad social de los empresarios fundadores, herederos y directores asalariados, indicaron que, entre los que no tenían estudios superiores, el ascenso social había sido mayor en los fundadores de empresas y en los herederos, que entre los directores asalariados; asimismo, la movilidad social ascendente era especialmente alta entre los fundadores de empresas de la «España semiindustrial». Estos autores señalan que las dos vías de movilidad social eran: o bien hacerse empresario después de un largo periodo de trabajo, o bien estudiar una carrera y seguir un camino de directivo.

17. La carencia de personal técnico es una dificultad muy enfatizada por los empresarios que iniciaron su actividad en aquellos años (García-Nieto, 1999). 
Yo me lo tenía que hacer todo, me tenía que hacer las facturas, tenía que salir a comprar, tenía que salir a vender, tenía que trabajar en la fábrica, tenia que hacer todo. Yo iba por las mañanas temprano a las seis y hasta las nueve que entraba el personal, al principio eran mujeres, hacía la preparación, porque iba en varias fases, yo iba preparando una primera fase y ya seguían con eso... Porque a vender cuando salía al principio, hasta Caravaca, Almoradí, Cehegín y eso, iba con una bicicleta de diez velocidades, después ya me compré una Gucci y creía que iba en un Rolls Royce, después de eso ya me compré otra moto que era una Ossa, y a los cinco o seis años de estar establecido, cuando ya podía pagar desahogadamente, me compré un coche usado que me lo traje de Madrid, un 600, por cierto FIAT, que llevaba más años que eso, pero que iba muy bien, por lo menos me desahogó del esfuerzo que hacía tener que andarme a lo mejor 90 kilómetros en bicicleta... Cuando tenía la Ossa iba a Játiva y a Valencia, salía a la seis de la mañana y a las nueve ya estaba allí, hacía la gestión de compras, yo salía a las once de allí y a las dos ya estaba en casa, en Molina, lo hacía con el fin de estar también en la fábrica y evitar hacer un desembolso de una comida fuera de mi casa, tenía dos cosas buenas: que estaba en mi negocio antes y que no me gastaba dinero.

Desde los comienzos de la empresa, quedaron marcadas las líneas de actuación y se fraguó una cultura empresarial que se seguiría a lo largo de la trayectoria de la empresa. Ésta se caracteriza por:

a) Una actividad polifacética, de implicación en todas las tareas.

b) Estrategia financiera de ahorrar y gastar sólo lo estrictamente necesario.

c) Clientela local reducida pero selecta y cumplidora con los pagos.

d) Sentido de la prudencia, de avanzar paso a paso sin pretensiones de crecimiento rápido, abarcando únicamente lo que puede realizar por los propios medios.

e) Esfuerzo personal: «trabajar mucho, como si fuera a destajo».

\section{Desarrollo de la empresa}

José vio una oportunidad y se esforzó para aprovecharla. Se arriesgó y compró una gran cantidad de cartón antes de que subiera el precio y trabajó duro para venderlo manufacturado a sus clientes. Para impulsar la empresa, afrontó un riesgo controlado que preveía que podía superar con su propia habilidad y esfuerzo. McClelland (1968) señala que los empresarios con alta motivación de logro aceptan riesgos moderados en función de su capacidad y desarrollan una actividad enérgica.

Con el buen resultado de esa operación, realizó nuevas inversiones y compró una nave para trasladar la fábrica. José se compara con otras empresas que se embarcan en grandes inversiones y por ello se encuentran en dificultades. Mantiene el principio de no realizar grandes desembolsos si no se tiene capacidad financiera, ni siquiera particulares, como casa o coches. Considera que, por su sentido de prudencia en los gastos, no ha tenido crisis en la empresa, y 
es una de las razones por las cuales el negocio ha ido bien. Los beneficios de la empresa se mantenían en reserva, y se reinvertían cuando era necesario. Ésa era la estrategia financiera: no pedir prestado a los bancos, tener liquidez y pagar al contado ${ }^{18}$ :

Las dificultades las tuve, como es lógico, al principio, porque yo empecé sin dinero, pero después yo no he tenido crisis como han tenido los demás, por una sencilla razón: me establecí en el cincuenta y tres y mi vivienda, pudiéndola haber comprado bastantes años antes como hicieron otros, yo seguía aún en una casa de alquiler, porque el dinero lo quería para desahogo del negocio. Por eso no recuerdo de ninguna época en la que tuviera dificultades. Aunque algún cliente hiciera suspensión de pagos, yo siempre tenía reservas para eso.

José es, ante todo, un comerciante. La estrategia de mercado está basada en mantener pocos clientes pero buenos, de acorde con una manera de actuar de priorizar el contacto y el conocimiento personal. Dedica una gran atención a los aspectos financieros y de gestión, paga al contado a los proveedores y obtiene mayores descuentos, con el principio de no abarcar más de lo que se puede controlar ${ }^{19}$.

\section{Aspiraciones}

Existe un paralelismo entre el proyecto personal y el proyecto de empresa, puesto que las aspiraciones personales son las que rigen la evolución y el desarrollo de la empresa. José rechaza la propuesta de otro empresario para asociarse y formar una empresa más grande. Prefiere dirigir una pequeña acorde con su capacidad personal. Del mismo modo, hay una gran correspondencia entre la familia y la empresa, pues, una vez que conoce que en su matrimonio no puede tener hijos, pierde la ilusión para emprender grandes proyectos, es consciente de que no va a formar una dinastía familiar y, por lo tanto, no tiene la preocupación, como ocurría en otros empresarios, de dejar un gran patrimonio empresarial para que lo continuara su descendencia:

A partir de que llegué a situarme con cierta garantía para poder pagar bien..., yo no me arriesgaba. Quizás sea también debido a la esperanza de tener hijos y después desengañarme, a pesar de poner todos los recursos, no los tuvimos. Yo tenía la ambición de situarme bien pero sin arriesgarme en exceso, porque no tenía necesidad, tenía cubiertas todas mis necesidades, tanto particulares como comerciales, y no tenía necesidad de arriesgarme.

18. Una de las claves de la supervivencia de las pequeñas empresas familiares ha sido mantener un criterio de prudencia y una política financiera de restricción de créditos y reinversión de los beneficios en la empresa (Bueno Asín, 1977).

19. Uno de los principales motivos de que durante la crisis del 73 muchas medianas empresas quebraran, fue que los empresarios tenían una formación técnica del negocio, pero no de gestión, y se descuidaron en ese aspecto (González Olivares, 1985). 
Cuando estábamos en la incertidumbre de si llegaríamos a tener familia o no, mi idea era seguir trabajando y seguir aumentando el negocio por si yo tenía hijos, darles un buen porvenir, y no vinieron. Otros que han empezado después que yo... tienen fábricas bastante mejor equipadas que la mía. Pero la ventaja que yo tengo respecto a ellos es que, teniendo menos capacidad de producción, yo trabajo con mi dinero, pago al contado y al personal lo tengo contento.

La aspiración personal de José continúa siendo la misma que cuando fundó la empresa: mantener un negocio que le permita vivir con comodidad. El objetivo es alcanzar una buena situación familiar y empresarial, y cuando se consigue, no existe la ambición de emprender nuevos proyectos. Esta aspiración es «familiar», y se caracteriza porque el empresario encauza su actividad a obtener un bienestar económico de la familia. Las empresas dirigidas por empresarios de «aspiraciones familiares" tienen un "comportamiento rígido" con pocos cambios en el tipo de clientes, en los productos, procesos productivos, distribución, promoción y tecnología, y con un mercado preferentemente local (Lafuente, Salas y Pérez, 1985).

\section{Esposa}

José, al contrario que otros empresarios que tenían varios hijos trabajando en el negocio, no contaba con más ayuda familiar que la de su esposa. Desde los inicios, la esposa compartió con él la aventura empresarial, primero trabajando como operaria en las máquinas y después en la oficina durante más de veinte años. Las esposas de los empresarios han desempeñado, en muchos casos, un papel destacado que, sin embargo, ha sido poco conocido y, por lo tanto, poco valorado. Además de apoyar al marido en su proyecto y en su ilusión empresarial, la esposa ha aportado su trabajo personal a la empresa de una manera discreta, en un segundo plano, dejando el protagonismo al marido (García-Nieto, 1999). En el interior de la empresa, se establece una división del trabajo que reproduce los roles del hogar familiar: el marido se encarga de las actividades en el exterior y la mujer se dedica a las tareas del interior de la empresa, poco vistosas pero no por eso menos importantes:

Cuando ya me casé, tres años después de establecerme, mi mujer, que había estado en una oficina, pues me ayudaba en la oficina y si hacía falta ponerse en una máquina, pues se ponía en la máquina.

\section{Tecnología}

La inversión en tecnología en la empresa de José se reduce a la estrictamente necesaria para renovar la maquinaria y mantener la producción, sin que la inversión en maquinaria le ocasione un desequilibrio financiero. Conoce otros empresarios que han pasado graves dificultades por hacer grandes inversiones. 
José adquiere la maquinaria que le resulta útil sin tener que efectuar un fuerte desembolso y, si es posible, la encarga a pequeños talleres locales. No tiene interés en disponer de una tecnología puntera, busca ante todo una maquinaria que cumpla su función y, si es preciso, la modifica y la adapta a las características y necesidades de la fábrica. Esta escasa cultura de la innovación es una consecuencia del propio entorno, que no ha favorecido la innovación tecnológica ${ }^{20}$ :

He comprado algunas máquinas, pero no de esas de treinta o cuarenta millones de pesetas, y a mí me hacen mi papel. Tengo una que me la ha hecho uno de Beniaján [pedanía de Murcia]... A mí me da igual que la chapa la lleve la máquina de una fábrica de Barcelona como que la lleve de Beniaján. A mí me está haciendo un servicio bueno, lo mismo que la otra.

\section{Relaciones con los clientes}

Desde los comienzos de la empresa, José se dedica a afianzar un mercado de ámbito local. Le gusta conocer personalmente a los clientes y mantener una relación directa con ellos. Ha seleccionado a los clientes con los que trabaja. Su máxima ha sido cumplir y que los clientes cumplan. De acuerdo con el principio de no deber dinero ni que le deban, cuando un cliente se encuentra en dificultades, le ofrece facilidades de pago. Aconseja a los clientes de manera amistosa, pero también pensado en su negocio. Transmite a sus clientes la filosofía de ir poco a poco. Si un cliente le hace un pedido importante y José cree que va a tener dificultades para pagar, le sugiere que realice un pedido menor y, cuando le haya dado salida, entonces que realice otro pedido. En la relación mercantil, se muestran las cualidades personales de este empresario: se valora la lealtad, la fidelidad y la honradez, se confía en la palabra de la persona, y hay una ayuda recíproca entre el vendedor y el cliente:

He tenido mercados fuera de Murcia, pero no me ha gustado... He tenido en cuenta una cosa, el cliente que ha sido adicto a mí, si en un momento se ha encontrado un poco apretado, le he ayudado... La clientela que tengo es muy selecta, sin salir de viaje para vender, ni casi visitarlos, por teléfono y por fax, me pasan los pedidos. No dependo de representantes, ni de viajantes, me siguen respondiendo... Valoro la fidelidad sobre todo y la honradez de la persona, para mí, tanto como el dinero, ha valido la honradez de la persona y cumplir a rajatabla. Desde el principio, ése ha sido siempre mi lema, el mismo lema que tengo para mis clientes.

20. Sobre la carencia de cultura de la innovación en la empresa española, véase: FUNDACIÓN COTEC PARA LA INNOvaCión TECNOLÓGICA (1998). El sistema español de innovación. Diagnósticos y recomendaciones. Libro Blanco. Madrid. 


\section{Empleados}

La empresa tiene catorce empleados, algunos con una antigüedad superior a treinta años. José ha mantenido, para la contratación de personal, el mismo criterio de austeridad que en el resto de la gestión de la empresa, ha contratado sólo al personal necesario. De esta manera, piensa que se evitaba tener que despedir personal en las épocas de crisis, como ocurría en otras fábricas. José cree que los empleados son conscientes de sus ventajas laborales y por eso no ha habido conflictividad ni siquiera en las situaciones sociales más tensas. José ha mantenido con los empleados una relación familiar y cercana, e incluso de amistad. Precisa que es una relación de confianza pero con un respeto mutuo, sin llegar a «intimar». Cada uno sabe donde está su sitio y, de esta manera, no ha sufrido conflictos con los trabajadores. Se enorgullece de que los empleados puedan acercarse a él, pedirle consejo o apoyo económico, ha realizado gestiones por ellos y ha ayudado a sus hijos. Avala a los empleados cuando solicitan un préstamo a los bancos, o bien, si no es mucha cantidad, se lo presta él sin cobrarles intereses. Siguiendo ese principio de confianza con los empleados pero sin «intimar», José no es muy proclive a organizar actos sociales con ellos fuera de la empresa. Esta relación de familiaridad pero con respeto era la que había vivido desde niño, la que existía en la empresa donde trabajaba su padre, y la que él percibió de empleado en el comercio de Caravaca. Cuando ha sido empresario, lo ha implantado y lo ha seguido en su propia empresa:

El trato que tenemos es familiar y personal. Nos tenemos mucho respeto, ahora no les doy ni me tomo demasiada confianza. Nosotros tenemos una amistad que no es normal entre un industrial y sus obreros. Tenemos confianza pero no una intimidad. Cuando hay intimidad, se llega a faltar al respeto. Yo no he tenido roces jamás con ninguno de ellos... Saben que pueden pedirme cualquier cosa que necesiten, porque si me la piden va a ser algo que ellos vean que es razonable, que yo se la pueda dar, como son los préstamos o alguna cosa de esas...

Este tipo de relaciones laborales ha sido calificado de paternalista. Aunque no existe un modelo único, suele producirse en empresas familiares pequeñas o medianas de cierta antigüedad, ubicadas en un entorno que tiene una alta interacción social. Al vínculo laboral, se superpone otro que establece unas relaciones personales de confianza mutua, lealtad y protección del empresario hacia los trabajadores. Michel Pinçon (1995) señala que el empresario es percibido por los trabajadores como un "padre mítico", es decir, un segundo padre más poderoso y más rico; la empresa es la segunda familia y el empresario adquiere el papel de "padre protector», realizando funciones de intermediación entre los trabajadores y la sociedad exterior. Bueno Asín (1977) indica que, en las empresas familiares, el empresario es más que un jefe, se convierte en consejero personal de los empleados. Este papel se agudiza cuando el empresario ha empezado desde abajo, los empleados lo ven como «uno de los suyos» 
que ha triunfado, y el empresario siente la responsabilidad de «cuidar» de los trabajadores (Martínez Hernáez, 1992).

Este modelo de paternalismo en la empresa, considerado tradicional, ha evolucionado y se ha adaptado dependiendo de las situaciones sociales y económicas en diversos tipos de empresas bajo diferentes formas. El «modelo japonés», que tantos ensalzadores ha tenido, se basa en unas relaciones regidas por la lealtad mutua, con un compromiso de la empresa con los trabajadores a cambio de una entrega total de los trabajadores a ella (Ouchi, 1984). Los avances sociales y, sobre todo, la democratización de las relaciones sociales han reducido el rol del empresario de intermediador y protector de los empleados. Sin embargo, el nuevo modelo organizativo de empresa flexible con proyectos a corto plazo hace necesario un "moderno paternalismo» con una gran compenetración y entendimiento mutuo entre el líder y su equipo.

\section{El retiro del empresario}

José ha estado al frente de la empresa hasta fechas recientes, cuando ya había cumplido los ochenta años de edad. Este retraso en la edad de jubilación estuvo motivado por el pánico a estar sin nada que hacer. Schumpeter (1976) afirma que el auténtico empresario sólo se retira cuando siente que se han agotado sus fuerzas físicas y piensa que ya no puede desempeñar adecuadamente su trabajo. No es una cuestión de necesidad económica, sino un miedo al vacío de la inactividad cuando la vida está centrada en torno a la propia empresa. Todo lo que ha tenido, se lo debe a la empresa, por ello continuar dirigiéndola es seguir sintiéndose con vitalidad:

Nada más ver en Molina, por el paseo Rosales, las pandas [de jubilados] que van de ocho o diez dando vueltas para acá o para allá, y gente que se les ve que están bien, si hay muchos de esos que yo creo que están en la rutina... Y me dice uno: «Pepe, no te retires todavía, por Dios! Porque si te jubilas estorbas en todas partes...». Yo les veo que lo pasan muy mal y entonces eso no lo quiero para mí, eso tiene que ser morirte poco a poco.

\section{Conclusiones}

En el transcurso del análisis de esta historia de vida, se ha ido mostrando como el empresario ha ido plasmando sus aspiraciones personales en el desarrollo de la empresa. En este caso, la aspiración del empresario era conseguir un bienestar económico en un entorno que propiciaba poco la movilidad social, y cuando considera que ha llegado a una situación adecuada que le permite vivir con confortabilidad, su principal preocupación es mantener la empresa sin interesarse por ampliar el negocio, captar nuevos clientes o realizar innovaciones tecnológicas. Si la aspiración del empresario hubiera sido otra, la empresa hubiera tenido una trayectoria diferente. 
El futuro creador de empresas interioriza sus experiencias vitales y las influencias que recibe del ámbito familiar y social; configura un universo íntimo con una escala de valores y de aspiraciones que propicia la creación de la empresa; constituye una guía para la trayectoria y la evolución de la empresa, y se manifiesta en el modo de gestionar la empresa y plantear sus objetivos y metas. El aprendizaje se recibe de una forma viva y directa de la familia, del trabajo, del grupo de amigos, de las interacciones sociales... Es la experiencia de la vida la que ejerce de maestra. La formación académica tiene un significado práctico y utilitario, interesa para adquirir una serie de conocimientos que puedan ser empleados para poder progresar social y económicamente en la vida. Importan más los contenidos de las materias que la obtención de un título.

Hay un momento clave para dar el paso definitivo a crear la empresa, caracterizado por una situación personal crítica donde se confrontan las aspiraciones interiores con la actividad laboral. En ese momento de ruptura con su vida anterior, el emprendedor acciona su sistema de aspiraciones y pone en marcha su idea de empresa motivado por los deseos y las ilusiones que ha estado alimentando.

La empresa es el instrumento utilizado para la realización de las aspiraciones particulares del empresario y, a su vez, éstas son las que determinan la evolución de la empresa. Que el desarrollo de la empresa vaya por una dirección u otra, depende de las inquietudes del fundador, que limitarán o propiciarán el crecimiento de la empresa. El fundador traslada a la gestión de la empresa su percepción del mundo, sus valores, sus aspiraciones y su manera de actuar, forjada y construida a través de las influencias recibidas y de las propias experiencias vitales. Forja una cultura empresarial que se manifiesta en los diferentes aspectos de la gestión, tales como las relaciones con los empleados, la administración, los financieros, la tecnología o los clientes. Mediante este proceso, la empresa es un espejo de la personalidad del empresario.

Por último, una observación acerca de los nuevos fundadores de empresas. Las nuevas tecnologías permiten realizar un mayor volumen de trabajo con menor esfuerzo y reducen el sacrificio personal. Además, la dinámica del entorno económico, tecnológico y social obliga a una permanente innovación y evolución en la empresa. Pero todo eso no quita para que el empresario continúe, de una manera o de otra, trasladando su mundo interior y sus aspiraciones personales a la empresa y la conduzca según esas aspiraciones. 


\section{Anexo códigos $^{21}$}

Infancia y juventud [0:0]
A. familia [0:0]
abuelos [1:10];
G. viajante $[0: 0]$
viajante $[1: 13]$

casa $[3: 13]$

padre [4:45]

corresponsal banco [2:18]

relaciones entre jefe y padre [1:7]

traslado a Molina [1:4]

viajante [1:3]

tíos [1:4]

B. estudios [0:0]

estudios primarios [2:9]

abandono de la escuela [2:10]

el maestro [1:7]

estudios mercantil [2:17]

evolución compañeros [1:15]

forma de estudiar [1:12]

no quiso el título [2:13]

C. forma de vida juvenil [0:0]

aspiraciones juveniles [1:2]

juegos infantiles [3:34]

relaciones sociales [6:44]

sobrevivir en la Guerra Civil [1:11]

D. primer trabajo [2:22]

conocimiento de la gente [2:29]

ingenio para obtener dinero [2:36]

primer sueldo [1:3]

relaciones compañeros [1:35]

negocios con los compañeros [1:15]

relaciones con el jefe [1:13]

relaciones otros comercios [1:5]

E. servicio militar [0:0]

servicio militar [1:23]

trabajo [1:6]

F. primeros años en Molina [0:0]

primeros años en Molina [1:56]

empleo de oficinista [1:4]

representante de libros [1:53]

clientes de libros [3:19]

agradecimientos [1:8]

sistema de cobro de libros [1:11]

forma de vida de viajante $[1: 16]$

interés por coger viajes [1:13]

Tánger [1:30]

cansancio de ser viajante $[1: 8]$

enseñanzas del viaje [3:8]

$H$. representante $[0: 0]$

representante [1:16]

I. pensamiento político [0:0]

Guerra Civil [1:21]

fusilamientos Guerra Civil [2:12]

represión y fus. después G. C. [3:31]

relaciones entre clases sociales [1:31]

partidos políticos [1:8]

La empresa [0:0]

A. fundación empresa [1:28]

compra maquinaria [1:8]

modificación máquinas [2:15]

motivaciones en la fundación [2:21]

pretendía algo más [1:6]

no se conocía el cartón [1:4]

salida del cuñado [1:6]

B. comienzos empresa [0:0]

dificultades económicas [1:24]

usurero [1:8]

ayuda amigo [1:13]

primeras actividades [1:7]

suministradores [1:11]

trabajo personal [1:25]

bicicleta [1:10]

hacía de todo [1:11]

montaje maquinaria autodidacta [1:17]

no tenía equipo familiar [1:7]

trabajar mucho [1:7]

viaje en el día [1:14]

pocos buenos clientes [1:40]

ayuda banco $[1: 40]$

21. El significado de los números entre corchetes es el siguiente: el primero, el número de veces que aparece la categoría y el segundo, el número de líneas que comprenden en el texto. Los corchetes con ceros están puestos por el investigador para denominar a las familias de códigos. 
C. impulso empresa oportunidad [0:0] oportunidad riesgo [1:11] riesgo moderado [1:10] trabajo oportunidad [1:9]

D. desarrollo empresa [0:0] ahorro, reservas [1:13] competencia [1:9] compra antes subida de precio [1:23] compra nave [1:31] lealtad banco [1:5] no letras devueltas [1:36] no pide créditos [1:18] no quiso una gran empresa [0:0] pago contado [2:18] proceso lento [1:21 referencia a otras empresas [1:17] sin riesgo excesivo [1:9] tamaño acorde familia [1:9]

E. esposa [1:29]

F. clientes [0:0] ayuda clientes [3:31] confiar en la palabra [1:7] consejos a los faroleros [1:23] fidelidad y honradez [1:11] mercado local [1:6] relaciones directas clientes [1:7] selección clientes [1:5]

G. innovación [1:21] adaptación máquinas [1:7]

H. empleados [0:0] confianza [2:14] empleado díscolo [1:56] empleados oficina [1:54] huelga [1:33] invitaciones [1:16] pocos empleados [1:20] préstamos a los empleados [1:25] propuesta fábrica empleados [1:52] remuneración [1:4] trato familiar y personal [1:11] vacaciones [1:18]

I. retiro $[1: 48]$

\section{Referencias bibliográficas}

ANDREU ABELA, Jaime (2001). Las técnicas de análisis de contenido: Una revisión actualizada. Sevilla: Fundación CENTRA.

Andreu Abela, Jaime; García-Nieto, Antonio; Pérez Corbacho, Ana (2007). Evolución de la teoría fundamentada como técnica de análisis cualitativo. Madrid: Centro de Investigaciones Sociológicas (CIS). Cuadernos Metodológicos, 40. BENDIX, Reinhard (1966) [1956]. Trabajo y autoridad en la industria. Buenos Aires: Eudeba.

BERICAT, E. (1998). La integración de los métodos cuantitativo y cualitativo en la investigación social. Barcelona: Ariel.

BLUMER, Herbet (1982) [1969]. El interaccionismo simbólico: perspectiva y método. Barcelona: Hora.

Bueno Asín, Jesús (1977). Las empresas familiares en Guipuizcoa. San Sebastián: Asociación Democrática Empresarial de Guipúzcoa.

Cabrera, Mercedes; Del Rey, Fernando (2002). El poder de los empresarios. Madrid: Taurus.

Cisneros Puebla, Cesar A. (2001). Análisis cualitativo asistido por computadora. Sevilla: Fundación CENTRA.

Collins, Orvis F.; Moore, David G.; Unwalla, Darab (1964). The Enterprising Man. Michigan: Michigan State University.

D'IrIBARNe, Philippe y otros (1998). Cultures et mondialisation. Gérer par delà les frontières. París: Éditions du Seuil.

D'IrIBARNE, Philippe (1993) [1989]. La logique de l'honneur. Gestion des entreprises et traditions nationales. París: Éditions du Seuil. 
GarCÍA-Nieto GÓmeZ-Guillamón, Antonio (1999). Liderazgo y cultura en la empresa familiar. Tesis doctoral inédita. Universidad de Murcia.

GLASER, Barney G. (1978). Theoretical Sensitivity. Mill Valley California: Sociology Press.

GLASER, Barney; STRAUSS, Anselm (1999) [1967]. The discovery of gorunded theory: strategies for qualitative research. Nueva York: Aldine de Gruyter.

GONZÁLEZ GONZÁLEZ, Manuel-Jesús (1979). La economía política del franquismo (1940-1970). Dirigismo, mercado y planificación. Madrid: Tecnos.

GONZÁLEZ OlIVARES, Luis (1985). "Crisis de la mediana empresa industrial, 19731977». Papeles de Economía Española, 22, p. 38-61. Madrid.

Jané SOLÀ, José (1978). «La política española y la PYME». Boletín de Estudios Económicos Universidad de Deusto, 104, p. 55-70. Bilbao.

KETS DE VRIES, Manfred (1977). «The entrepreneurial personality: a person at the crossroads». The Journal of Management Studies, vol. 14, febrero, p. 34-57.

KUCKARTZ, Anne M.; KUCKARTZ, Udo (2002). Qualitative text analysis with Maxqda. Sevilla: Fundación CENTRA.

Lafuente Félez, Alberto; Salas Fumás, Vicente; Pérez Simarro, Ramón (1985). «Tipos de empresario y empresa. El caso de las nuevas empresas españolas». Economía Industrial, noviembre-diciembre, p. 139-151. Madrid.

LiNZ, Juan; Miguel, Amando de (1963). «Fundadores, herederos y directores en las empresas españolas 2a parte». Revista Internacional de Sociología, 82, p. 185-216.

- (1964a). «Fundadores, herederos y directores de las empresas españolas $3^{\text {a }}$ parte». Revista Internacional de Sociología, 85, p. 5-28.

- (1964b). «Movilidad social del empresariado español I». Fomento Social, 75, p. 259-276.

- (1964c). «Movilidad social del empresariado español II». Fomento Social, 76, p. 363-390.

- (1964d). «Origen social de los empresarios». Boletín informativo del Seminario de Derecho Politico, 31, p. 39-88. Salamanca.

- (1966). Los empresarios ante el poder público. Madrid: Instituto de Estudios Políticos.

Lladró, José (2002). Pasajero de la vida. Recuerdos y opiniones de un emprendedor. Barcelona: Planeta.

MACClELlAND, David C. (1968) [1961]. La sociedad ambiciosa: Factores psicológicos en el desarrollo económico. 2 vols. Madrid: Guadarrama.

MARTÍNEZ HERNÁEZ, Ángel (1992). "Cultura status y experiencia individual. Una etnografía de los empresarios de limpieza barceloneses». Antropología: Revista de Pensamiento Antropológico y Estudios Etnográficos, 2, p. 103-121.

Nueno, Pedro (1994). Emprendiendo: El arte de crear empresas y sus artistas. Bilbao: Deusto.

OuCHI, William (1984) [1981]. Teoría Z. Barcelona: Orbis.

PARSONS, Talcott (1982) [1951]. El sistema social. Madrid: Alianza Editorial.

PiCO, José (1976). Empresario e industrialización. El caso valenciano. Madrid: Tecnos. PinÇON, Michel (1995). «Un patronat paternel». En: Actes de la Recherche en Sciences Sociales, vol. 57-58, p. 95-102.

Plummer, Ken (2001). Documents of life 2. An invitation to a critical humanism. Londres: SAGE Publications.

SAINSAUlieu, Renaud (1997). Sociologie de l'entreprise: organisation, culture et développement. París: Presses de Science Politiques.

SCHEIN, Edgar (1988) [1985]. La cultura empresarial y el liderazgo: Una visión dinámica. Barcelona: Plaza y Janés. 
SCHUMPETER, Joseph (1976) [1912]. Teoría del desenvolvimiento económico. México: Fondo de Cultura Económica.

STRAUSS, Anselm L. (1996) [1987]. Qualitative Analysis for Social Scientists. Cambridge: Cambridge University Press.

STRAUSS, Anselm; CORBIN, Juliet (1998). Basics of qualitative research. Techniques and procedures for developing grounded ( $2^{\mathrm{a}}$ ed.). Londres: SAGE Publications.

TORRES, Eugenio (1995). «El empresario». En: GARCÍA DELGADO (dir.). Lecciones de economía española. Madrid: Cívitas.

TORTELla, Gabriel (1994). El desarrollo de la España contemporánea. Historia económica de los siglos XIX y XX. Madrid: Alianza Editorial.

VALLÉS MARTínEZ, Miguel S. (2000). «La grounded theory y el análisis cualitativo por ordenador». En: GARCÍA F. Manuel; IBÁÑEZ, Jesús; AlVIRA, Francisco (coords.). El análisis de la realidad social: Métodos y técnicas de investigación. Madrid: Alianza Editorial, p. 575-603.

- (2001). Ventajas y desafíos del uso de programas informáticos en el análisis cualitativo. Una reflexión metodológica desde la grounded theory y el contexto de la investigación social española. Sevilla: Fundación CENTRA.

Veciana, José María (1989). "Características del empresario en España». Papeles de Economía Española, 39, p. 19-36.

WeBER, Max (1997) [1904-1905]. La ética protestante y el espíritu del capitalismo. Barcelona: Península.

Weiztman, Eben A. (2003). «Software and Qualitative Research». En: DenZIN, Norman K.; LINCOLN, Yvonna S. (coords.). Collecting and Interpreting Qualitative Materials (2a ed.). Londres: Sage Publicatons, p. 310-339. 